\title{
Evaluation of Sexual Function of Postmenopausal Brazilian Women
}

\author{
Alinne Alves Inuy ${ }^{*}$, Ana Maria Menezes ${ }^{1}$, Fadlo Fraige Filho ${ }^{2}$, Caroline Alves Moreira da Silva ${ }^{1}$, \\ Dolores Pardini ${ }^{1}$
}

\begin{abstract}
Objectives: This study analyzed for the first time the effects of diabetes mellitus on the sexual function of Brazilian postmenopausal women.

Materials and Methods: In total, 184 postmenopausal participants were selected after meeting the inclusion criteria of occurrence of menopause, diagnosis of type 2 diabetes (T2D), $\geq 1$ year stable heterosexual relationship, active sexual life for $>6$ months, controlled associated chronic diseases, and absence of recent acute illness or psychiatric diseases. The participants were categorized into two groups, with and without T2D (control group). The control group comprised 84 women without diabetes, with mean 55 years of age, whereas the diabetes group comprised 100 women with T2D with a mean 59 years of age. Each participant filled out the nine-item Female Sexual Function Index (FSFI) questionnaire. The analyzed domains included desire, arousal, lubrication, orgasm, satisfaction, and pain. An FSFI score $\leq 26.5$ determined the occurrence of sexual dysfunction (SD).

Results: The prevalence of SD was significantly increased in women with T2D (85\%) compared with controls $(69 \% ; P=0.001)$. Women in the T2D group had lower mean total FSFI score when compared with those in the control group $(P=0.004)$. As for specific questionnaire items, we found significant differences in regards to decreased arousal $(P=0.004)$, desire $(P=0.001)$, lubrication $(P=0.015)$, orgasm $(P=0.019)$, satisfaction $(P=0.002)$, and pain $(P=0.002)$ in the T2D group. SD was associated with diabetes duration in the T2D group and with age $(P=0.001)$ and menopause duration $(P=0.001)$ in both groups.

Conclusions: Among postmenopausal women in Brazil, a diagnosis of diabetes increased SD prevalence and had an impact on arousal, desire, lubrication, orgasm, satisfaction, and pain.

Keywords: Diabetes, Menopause, Sexual dysfunction
\end{abstract}

\section{Introduction}

Sexual function is a fundamental component of a woman's healthy life (1-3). Still, female sexual dysfunction (SD) is largely unexplored in the literature and, specifically among diabetic women compared with men, infrequently questioned during evaluation of chronic diabetic complications (1-5). In fact, fewer than $10 \%$ of the physicians question their female patients about sexual function, despite $72 \%$ of these patients reporting that they would like to discuss this subject $(1,3)$.

Between $40 \%-45 \%$ of the women are estimated to present SD (3). In the few studies investigating female SD in Brazil, the frequency increased to $49 \%$ with age, multiparity, and menopause, with approximate prevalence of $26 \%$ for lack of desire, $23 \%$ for pain, and $21 \%$ for orgasmic dysfunction $(6,7)$.

The female sexual health undergoes several changes throughout life and varies according to age, hormonal variations, and chronic diseases, which may contribute to the development of SD. Menopause is associated with SD by imposing changes in lifestyle and vaginal physiology, while some studies also suggest an increased risk of female SD associated with a progression to diabetes mellitus (8).
The first link between female SD and diabetes was established by Kolodny in 1971(9). However, the data related to the prevalence of this condition is still conflicting and reported to range between $25 \%$ and $71 \%$, according to Pontiroli et al (5). This variation reflects differences in ethnicity and culture of the population under evaluation, criteria for study inclusion (such as age and type/duration of diabetes), and tools used to assess SD (5,10-12).

Enzlin et al have found the occurrence of SD in 25\% and $27 \%$ of diabetic men and women, respectively, although the correlation among women was only associated with depression (13). Duman studied patients with types 1 (T1D) and 2 diabetes (T2D) and found that in both groups, SD correlated significantly with diabetes type and duration, in addition to glycosylated hemoglobin (HbA1C) levels, but not with age, schooling, overall monthly income, status of employment, duration of marriage, and childbearing (14). Taloyan et al studied only patients with T2D and reported that age, civil status, and the presence of diseases other than diabetes also affected sexual satisfaction (15).

Based on the considerations above, this study aimed at analyzing for the first time the impact of diabetes on the 
sexual function of postmenopausal Brazilian women.

\section{Materials and Methods}

Participants and Data Collection

This cross-sectional, retrospective study took place between January 2013 and January 2015 at the National Association of Diabetes Care and Menopause Outpatient Clinic at Federal University of São Paulo. In total, 184 women with a postmenopausal status were subdivided into groups with and without T2D (diabetes group and control group, respectively). The Female Sexual Function Index (FSFI) was applied to assess sexual function. This tool has been validated in several studies for the ages 18-74 years and has been translated into Portuguese. The questionnaire includes 19 items assessing the respondent's sexual function during the prior 4 weeks and yields scores in six individual domains (sexual desire, arousal, lubrication, orgasm, satisfaction, and pain), in addition to an overall sexual function index. The total score ranges from 2-36, in which the highest scores indicate a better sexual function. The total score of $\leq 26.5$, which has been previously validated, was applied in the present study to classify subjects as having SD $(16,17)$. The objectives of the study were informed to the participants, who agree to take part in the research after signing a consent form.

\section{Inclusion Criteria}

The inclusion criteria for initial enrollment of the subjects were the occurrence of natural menopause, a body mass index (BMI) of $18.5 \mathrm{~kg} / \mathrm{m}^{2}$ or greater but equal to or lower than $29.99 \mathrm{~kg} / \mathrm{m}^{2}$, the presence of a $>1$ year stable heterosexual relationship, an active sexual life during the prior 6 months, controlled concomitant chronic diseases (no therapeutic changes during the previous 6 months), and absence of recent acute illnesses, psychiatric diseases, hormonal therapy, and use of medications with the potential to interfere with sexual function. Additional criteria were applied to the diabetic group, including a diagnosis of $\mathrm{T} 2 \mathrm{D}$, absence of severe chronic diabetic complications that the participant related as a limiting factor for sexual practice, HbAlc levels $<8.0 \%$, and absence of insulin therapy.

Statistical Analyses

We calculated the differences between groups using paired Student's t test. $\mathrm{P}$ values $<0.05$ were deemed significant.

\section{Results}

The participants' mean age was $55 \pm 4$ years among controls and $56 \pm 5$ years among women with T2D. Menopause duration was $8 \pm 5$ years among controls and 9 \pm 5 years among participants with T2D. Diabetes duration was $11 \pm 6$ years.

The SD prevalence was significantly greater in the group with T2D (85\%) versus the group comprising control participants $(69 \%)(P=0.001$; relative risk $[R R] 1.28,95 \%$ confidence interval 1.09-1.51). The mean overall FSFI score was lower in the T2D group $(13.48 \pm 10)$ versus the control group $(18.14 \pm 11 ; P=0.004)$. As for specific items in the questionnaire, significant differences were found in the diabetic group for decreased arousal $(P=0.004)$, desire $(P=0.001)$, lubrication $(P=0.015)$, orgasm $(P=0.019)$, satisfaction $(P=0.002)$, and pain $(P=0.002)$. SD was associated with T2D duration in the diabetes group and with age $(P=0.001)$ and menopause duration $(P=0.001)$ in both the groups.

\section{Discussion}

The prevalence of SD among women with diabetes is unclear. Estimates indicate that about $27 \%$ of the women with T1D report SD in comparison to $15 \%$ of control subjects (18). We compared two groups of Brazilian women at risk of SD due to menopause and found that SD affected more women with T2D (85\%) than controls (69\%).

We reported for the first time in a Brazilian cohort that postmenopausal women with diabetes have more severe SD compared with nondiabetic ones and that sexual function was inversely related to age and duration of menopause and diabetes. This may have occurred due to a negative impact of diabetes on desire, arousal, lubrication, orgasm, pain, and satisfaction in the study population(11, 19-21).

Ali et al have shown that $\geq 50$-year-old women with diabetes report more frequently the occurrence of decreased sexual desire than those without diabetes matched for age $(79.5 \%$ and 59\%, respectively) (22). Among women with $\mathrm{T} 2 \mathrm{D}$, the incidence of decreased libido was higher in comparison to a healthy control group ( $77 \%$ and $20 \%$, respectively).

The pathophysiologic mechanism of SD in women with diabetes is still unclear (23). The vagina has an important role in a woman's sexual function; the vaginal tissue responds directly to estradiol variations during a woman's life and undergoes structural and functional changes (24). Insulin interferes with ovarian aromatase activity, whose reduction may result in decreased estradiol levels (25). Diabetes seems to impose a negative effect on steroidogenesis and decreases expression of the estrogen receptor- $\alpha$ (ER $\alpha)$, aquaporin-2 (AQP2), androgen receptor $(A R)$, and progesterone receptor $(P R)$ genes in experimental studies $(8,11,24)$.

Recently, Baldassarre et al have reported that ER $\alpha$ expression in the vaginal tissue in postmenopausal women was not significantly different than that in women without diabetes, although the $A R$ expression was decreased. Important vascular changes have been observed such as increased vessel density and poor differentiation and, eventually, lack of vascular lumen. In addition, the isoforms endothelial (eNOS) and neuronal (nNOS) nitric oxide synthase have been described as significantly reduced in the vaginal tissue, which may reduce the vaginal hemodynamic response (8). Hyperglycemia apparently decreases hydration of mucus membranes and, in addition to vascular modifications, compromises vaginal lubrication, leading to dyspareunia $(8,24,26,27)$. 
Dissatisfaction was another finding in our study. There is considerable disagreement in the literature in regards to female sexual satisfaction in diabetes, which could vary according to the study's design, and the participants' age, ethnicity, and partner's sexual performance $(12,15,26,28)$.

Due to the effect on sexual function caused by chronic complications, postmenopausal women with a diagnosis of diabetes must be questioned by their physicians regarding their sexual function in order to receive appropriate treatment (29). More studies should be conducted evaluating the sexual function of postmenopausal women with diabetes (30).

\section{Conclusions}

Diabetes was associated with SD in a Brazilian sample of women with a postmenopausal status. SD presented an increased prevalence, risk, and severity among menopausal women with diabetes compared with controls.

\section{Conflict of Interests}

Authors declare that they have no conflict of interests.

\section{Ethical Issues}

A consent form was delivered and signed by all participants in accordance with local ethics committee regulations.

\section{Financial Support}

None.

\section{References}

1. Kingsberg SA, Iglesia CB, Kellogg S, Krychman ML. Handbook on female sexual health and wellness. Washington, DC: Association of Reproductive Health Professionals; 2011.

2. Lusti-Narasimhan M, Beard JR. Sexual health in older women. Bull World Health Organ. 2013;91(9):707-709. doi:10.2471/BLT.13.119230

3. da Silva Lara LA, de Sa Rosa E Silva AC, Romao AP, Junqueira FR. Abordagem das disfuncoes sexuais femininas. Rev Bras Ginecol Obstet. 2008;30(6):312-321. doi:10.1590/ S0100-72032008000600008

4. Lewis RW, Fugl-Meyer KS, Bosch R, et al. Epidemiology/ risk factors of sexual dysfunction. J Sex Med. 2004;1(1):3539. doi:10.1111/j.1743-6109.2004.10106.x

5. Pontiroli AE, Cortelazzi D, Morabito A. Female sexual dysfunction and diabetes: a systematic review and metaanalysis. J Sex Med. 2013;10(4):1044-1051. doi:10.1111/ jsm.12065

6. Mendonca CR, Silva TM, Arruda JT, Garcia-Zapata MT, Amaral WN. Female sexual function: normal and pathological aspects, prevalence in Brazil, diagnosis and treatment. Femina. 2012;40(4):195-202.

7. Silva GM, Lima SM, Moraes JC. [Evaluation of sexual function in postmenopause women with metabolic syndrome]. Rev Bras Ginecol Obstet. 2013;35(7):301-308. doi:10.1590/s0100-72032013000700004

8. Baldassarre M, Alvisi S, Berra M, et al. Changes in vaginal physiology of menopausal women with type 2 diabetes. J Sex Med. 2015;12(6):1346-1355. doi:10.1111/jsm.12906
9. Kolodny RC. Sexual dysfunction in diabetic females. Diabetes. 1971;20(8):557-559.

10. Lindau ST, Tang H, Gomero A, et al. Sexuality among middle-aged and older adults with diagnosed and undiagnosed diabetes: a national, population-based study. Diabetes Care. 2010;33(10):2202-2210. doi:10.2337/dc100524

11. Esposito K, Maiorino MI, Bellastella G, Giugliano F, Romano M, Giugliano D. Determinants of female sexual dysfunction in type 2 diabetes. Int J Impot Res. 2010;22(3):179-184. doi:10.1038/ijir.2010.6

12. Mazzilli R, Imbrogno N, Elia J, et al. Sexual dysfunction in diabetic women: prevalence and differences in type 1 and type 2 diabetes mellitus. Diabetes Metab Syndr Obes. 2015;8:97-101. doi:10.2147/dmso.s71376

13. Enzlin P, Mathieu C, Van Den Bruel A, Vanderschueren D, Demyttenaere K. Prevalence and predictors of sexual dysfunction in patients with type 1 diabetes. Diabetes Care. 2003;26(2):409-414.

14. Duman NB. Frequency of sexual dysfunction and its causative factors among diabetic women in Turkey. Pak J Med Sci. 2014;30(3):558-563. doi:10.12669/pjms.303.4638

15. Taloyan M, Wajngot A, Johansson SE, Tovi J, Sundquist J. Ethnic differences in dissatisfaction with sexual life in patients with type 2 diabetes in a Swedish town. BMC Public Health. 2010;10:536. doi:10.1186/1471-2458-10-536

16. Hentschel H, Alberton DL, Capp E, Goldim JR, Passos EP. Validation of the Female Sexual Function Index (FSFI) for Portuguese language. Rev HCPA. 2007;27(1):10-14.

17. Rosen R, Brown C, Heiman J, et al. The Female Sexual Function Index (FSFI): a multidimensional selfreport instrument for the assessment of female sexual function. J Sex Marital Ther. 2000;26(2):191-208. doi:10.1080/009262300278597

18. Enzlin P, Mathieu C, Van den Bruel A, Bosteels J, Vanderschueren D, Demyttenaere K. Sexual dysfunction in women with type 1 diabetes: a controlled study. Diabetes Care. 2002;25(4):672-677.

19. Bargiota A, Dimitropoulos K, Tzortzis V, Koukoulis GN. Sexual dysfunction in diabetic women. Hormones (Athens). 2011;10(3):196-206.

20. Rutherford D, Collier A. Sexual dysfunction in women with diabetes mellitus. Gynecol Endocrinol. 2005;21(4):189-192. doi:10.1080/09513590400021110

21. Bancroft J. The endocrinology of sexual arousal. J Endocrinol. 2005;186(3):411-427. doi:10.1677/joe.1.06233

22. Abu Ali RM, Al Hajeri RM, Khader YS, Shegem NS, Ajlouni KM. Sexual dysfunction in Jordanian diabetic women. Diabetes Care. 2008;31(8):1580-1581. doi:10.2337/dc080081

23. Fitzpatrick LA. Libido and the perimenopausal women. Menopause. 2004;11(2):136-137.

24. Traish AM, Cushman T, Hoyt R, Kim NN. Diabetes attenuates female genital sexual arousal response via disruption of estrogen action. Korean J Urol. 2009;50(3):211223. doi:10.4111/kju.2009.50.3.211

25. Chabrolle C, Jeanpierre E, Tosca L, Rame C, Dupont J. Effects of high levels of glucose on the steroidogenesis and the expression of adiponectin receptors in rat ovarian cells. Reprod Biol Endocrinol. 2008;6:11. doi:10.1186/14777827-6-11 
26. Dimitropoulos K, Bargiota A, Mouzas O, Melekos M, Koukoulis G, Tzortzis V. Dissatisfaction with male sexual performance and female sexual dysfunction in women with type 1 diabetes. Int J Impot Res. 2015;27(1):25-28. doi:10.1038/ijir.2014.21

27. Dimitropoulos K, Bargiota A, Mouzas O, Melekos M, Tzortzis V, Koukoulis G. Sexual functioning and distress among premenopausal women with uncomplicated type 1 diabetes. J Sex Med. 2012;9(5):1374-1381. doi:10.1111/ j.1743-6109.2012.02664.x

28. Hartmann U, Heiser K, Ruffer-Hesse C, Kloth G. Female sexual desire disorders: subtypes, classification, personality factors and new directions for treatment. World J Urol. 2002;20(2):79-88. doi:10.1007/s00345-002-0280-5

29. Enzlin P, Mathieu C, Vanderschueren D, Demyttenaere K. Diabetes mellitus and female sexuality: a review of 25 years' research. Diabet Med. 1998;15(10):809-815. doi:10.1002/ (sici) 1096-9136(199810)15:10<809::aid-dia689>3.0.co;2-z

30. Stuenkel CA. Menopause, hormone therapy and diabetes. Climacteric. 2017;20(1):11-21. doi:10.1080/13697137.2016 .1267723

(c) 2018 The Author (s); This is an open-access article distributed under the terms of the Creative Commons Attribution License (http://creativecommons.org/licenses/by/4.0), which permits unrestricted use, distribution, and reproduction in any medium, provided the original work is properly cited. 